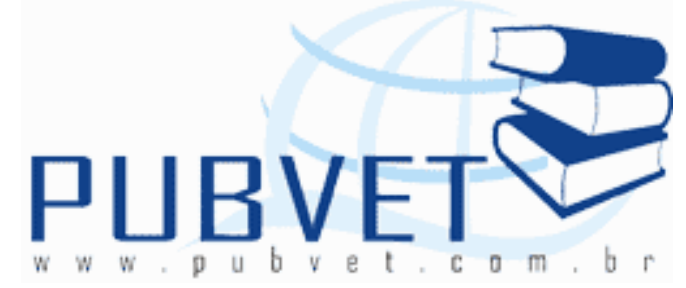

PUBVET, Publicações em Medicina Veterinária e Zootecnia.

\title{
Contagem bacteriana total do leite cru produzido no Paraná, São Paulo e Minas Gerais após implementação da Instrução Normativa $n^{\circ} 51 / 2002$
}

\footnotetext{
Mayara Souza Pinto ${ }^{1 *}$; Laerte Dagher Cassoli²; Paulo Fernando Machado ${ }^{2}$; Kênia de Fátima Carrijo ${ }^{3}$; Robson Maia Franco ${ }^{4}$.
}

${ }^{1 *}$ Fiscal Federal Agropecuário do Ministério da Agricultura, Pecuária e Abastecimento (MAPA). Departamento de Inspeção de Produtos de Origem Animal (DIPOA), Divisão de Inspeção de Leite e Derivados (DILEI), Endereço: Esplanada dos Ministérios - Bloco D - Brasília-DF, Brasil. Telefone: (61) 32182680/2192. E-mail: mayara.pinto@agricultura.gov.br.

${ }^{2}$ Pesquisadores da Clínica do Leite, Universidade de São Paulo (USP), Escola Superior de Agricultura Luis de Queiroz (ESALQ), Departamento de Zootecnia, Piracicaba-SP, Brasil.

${ }^{3}$ Docente da Faculdade de Medicina Veterinária, Universidade Federal de Uberlândia (UFU). Uberlândia-MG, Brasil.

${ }^{4}$ Docente da Faculdade de Veterinária da Universidade Federal Fluminense (UFF). Niterói-RJ, Brasil.

\section{Resumo}

Neste trabalho objetivou-se avaliar os resultados das análises da Contagem Bacteriana Total em amostras de leite cru refrigerado coletadas de tanques refrigeradores localizados em São Paulo, Paraná e Minas Gerais no período de 
setembro de 2006 a agosto de 2007, verificando o atendimento à Instrução Normativa N051, de 18 de setembro de 2002, vigente na época, no que se refere à porcentagem de amostras em desacordo à norma e às médias geométricas obtidas ao longo dos meses avaliados. O valor máximo de CBT em leite cru refrigerado admitido pela referida legislação era de até $1 \times 10^{6} \mathrm{UFC} / \mathrm{mL}$. O Estado do Paraná teve como média 16\% de amostras fora do padrão, Minas Gerais, $20 \%$ e São Paulo $24 \%$. As médias geométricas variaram entre 74.000UFC/mL e $394.000 \mathrm{UFC} / \mathrm{mL}$. Os resultados obtidos permitiram inferir que embora a porcentagem de amostras de leite cru refrigerado em desacordo com a legislação estivesse abaixo da média descrita na literatura e as médias geométricas de CBT estivessem dentro dos parâmetros exigidos na norma vigente na época das análises, os valores ainda se encontravam em níveis elevados.

Palavras-chave: leite, IN N51/2002, qualidade do leite, CBT, contaminação

\section{Total bacteria count in raw milk from Parana, São Paulo, Minas Gerais states after implementation of the Normative Instruction} $\mathrm{N}^{\circ} 51 / 2002 /$ Ministry of Agriculture, Livestock and Food Suply (MAPA).

\section{Abstract}

This work aimed to evaluate the results of analyzes of total bacteria count in raw milk samples collected from refrigerated coolers tanks located in Sao Paulo, Parana and Minas Gerais from September 2006 to August 2007, verifying the compliance with the Normative Instruction $N^{\circ} 51$, September 18, 2002, in force at the time, with regard to the percentage of samples in disagreement with the standard and geometric means obtained over the months evaluated. The maximum value of TBC in refrigerated raw milk allowed by this legislation was to $1 \times 10^{6} \mathrm{CFU} / \mathrm{mL}$. The Paraná state had a mean of $16 \%$ of samples outside the standard, Minas Gerais, Sao Paulo $20 \%$ and $24 \%$. The geometric means ranged between $74.000 \mathrm{UFC} / \mathrm{mL}$ to $394.000 \mathrm{CFU} / \mathrm{ml}$. The results allowed inferring that although the percentage of raw milk samples 
refrigerated incompliance with the legislation was below the average reported in the literature and the geometric means of TBC were within the parameters required in current regulations at the time of analysis, the values still found at high levels.

Keywords: Milk, IN N51/2002, milk quality, TBC, contamination

\section{INTRODUÇÃO}

O leite é um dos principais produtos que compõem a dieta dos consumidores brasileiros, seja por consumo direto ou pelo de seus derivados. Isso se deve ao fato de ser um alimento com alto valor nutritivo, agregando num mesmo produto uma importante fonte de minerais (cálcio, fósforo, potássio, magnésio, sódio), vitaminas, proteínas, gorduras e carboidratos. Entretanto, devido a sua composição completa e balanceada, o leite é um substrato ideal para o desenvolvimento de diversos grupos de microrganismos. Entre os quais estão bactérias, leveduras, fungos, que podem causar significativas alterações sensoriais e tecnológicas no leite e, quando patogênicos, riscos à Saúde Coletiva ${ }^{1,2}$. Dentre estes microrganismos, os que possuem maior representatividade são as bactérias ${ }^{3,4}$.

Neste sentido, a qualidade do leite cru está intimamente relacionada com o grau de contaminação inicial e com o tempo e a temperatura em que o leite permanece desde a ordenha até o processamento. Em geral, quanto maior a carga microbiana presente e quanto mais alta for a temperatura na qual o leite permanece (próxima de $30^{\circ} \mathrm{C}$ ), menor será o seu tempo de conservação ${ }^{5}$.

Visando promover a melhoria na qualidade do leite produzido no país, o Ministério da Agricultura Pecuária e Abastecimento (MAPA) publicou em 2002, a Instrução Normativa n051, de 18 de setembro de $2002^{6}$, na qual foram estabelecidos critérios de qualidade que os diferentes tipos de leite deveriam ter e ainda a forma como o leite cru deveria ser transportado, além de estipular o resfriamento do leite, preferencialmente, nas fazendas. Posteriormente, esta legislação foi alterada em virtude da publicação da 
Instrução Normativa n62, de 29 de dezembro de 20117 , na qual foram estabelecidos novos parâmetros relativos à qualidade, além de estabelecer aspectos de produção e identidade dos diferentes tipos de leite.

Este trabalho foi desenvolvido com o objetivo de avaliar os resultados das análises de Contagem Bacteriana Total (CBT) em amostras de leite cru refrigerado produzido nos Estados de São Paulo, Minas Gerais e Paraná durante os meses de setembro de 2006 a agosto de 2007, verificando o atendimento à Instrução Normativa No51, de 18 de setembro de 2002 ${ }^{6}$, vigente na época, no que se refere à porcentagem de amostras em desacordo à norma e às médias geométricas obtidas ao longo dos meses avaliados.

\section{MATERIAL E MÉTODO}

\subsection{Amostragem}

Foram utilizados os resultados das amostras de leite de tanques refrigeradores de propriedades leiteiras que fornecem matéria-prima para 170 estabelecimentos fiscalizados pelo Serviço de Inspeção Federal (SIF) dos estados do Paraná, Minas Gerais e São Paulo no período de setembro de 2006 a agosto de 2007. O material utilizado na coleta foi fornecido pelo laboratório aos técnicos dos laticínios, treinados para executar as coletas nos tanques resfriadores de leite nas propriedades, a ser entregue para seu respectivo estabelecimento beneficiador

O responsável pela coleta realizou os seguintes procedimentos de acordo com Manual de Instruções para coleta e envio de amostras de leite para análise, segundo Cassoli et $\mathrm{al}^{8}$. Tais procedimentos são os seguintes: identificação do frasco com etiqueta de código de barras; homogeneização do leite do tanque acionando-se o agitador por um tempo determinado; transferência do leite para o frasco com o auxilio de uma concha; adição de quatro gotas do conservante Azidiol no leite que acabou ser transferido para o 
frasco; homogeneização do leite, invertendo-se o frasco delicadamente por várias vezes.

Todas as amostras de leite usadas para a realização de Contagem Bacteriana Total (CBT) foram mantidas refrigeradas, à temperatura inferior a $10^{\circ} \mathrm{C}$ desde a coleta até a chegada ao laboratório.

Todas as amostras foram analisadas pela Clínica do Leite, da Escola Superior de Agricultura Luís de Queiroz (ESALQ) da Universidade de São Paulo (USP), laboratório credenciado na Rede Brasileira de Qualidade do Leite (RBQL).

\subsection{CONTAGEM BACTERIANA TOTAL (CBT)}

A contagem bacteriana foi realizada em equipamento BactoCount IBC, automático que utiliza a citometria de fluxo para a enumeração rápida de bactérias individuais do leite cru. A análise consistiu dos seguintes procedimentos: o leite amostrado foi colocado e aquecido num carrossel a $50^{\circ} \mathrm{C}$ e incubado numa solução tampão para clarificação; a seguir, uma enzima proteolítica e um marcador fluorescente de DNA foram adicionados para romper as células somáticas, solubilizar os glóbulos de gordura e proteínas, permeabilizar as bactérias e corar o DNA/RNA; após, a mistura foi sonificada duas vezes para a degradação química das partículas que poderiam interferir e romper as colônias remanescentes de bactérias, melhorando a identificação bacteriana e reduzindo a fluorescência de base. Após um período de incubação, a solução foi transferida para a citometria de fluxo, onde as bactérias foram alinhadas e expostas a um feixe de laser fluorescente. O sinal de fluorescência foi coletado por células óticas, filtrado e detectado com um foto-multiplicador altamente sensível. A intensidade e largura dos pulsos de fluorescência foram registrados e utilizados como parâmetros. Assim, os pulsos foram classificados e traduzidos em contagem individual de bactérias e após a calibração do equipamento, transformadas em UFC/mL. 


\subsection{QUANTIDADE DE AMOSTRAS ANALISADAS MENSALMENTE EM CADA ESTADO E NO TOTAL}

Foram analisadas 224.244 amostras no total, durante os meses de setembro de 2006 a agosto de 2007, sendo que a maioria das amostras $(50,66 \%)$ foi procedente de produtores de Minas Gerais, seguido por São Paulo $(40,59 \%)$ e o restante por produtores situados no Estado do Paraná $(8,74 \%)$.

\subsection{ANÁLISE DOS DADOS}

Para a análise dos resultados de CBT foram estabelecidas as suas médias geométricas mensais e o percentual de amostras que apresentaram resultados nas análises situadas fora do limite máximo regulamentado na IN N51/2002.

$O$ banco de dados e as tabelas e gráficos foram construídos na planilha Excel e as análises estatísticas descritivas foram realizadas nos programas $R^{9}$ ( $R$ Project for Statistical computing) para média geométrica e MINITAB ${ }^{10}$ para microcomputador, para análise descritiva.

\section{RESULTADOS}

\subsection{PORCENTAGEM DE AMOSTRAS NÃO CONFORMES SEGUNDO A INSTRUÇÃO NORMATIVA N051/2002 NO TOTAL E POR ESTADO PARA CBT}

A porcentagem de amostras com resultados superiores a 1.000 .000 UFC/mL e, portanto em desacordo com a Instrução Normativa N051/2002, vigente no período que estas amostras foram realizadas, variou de $15,47 \%$ a $30,49 \%$ ao longo dos meses no total de análises, conforme observam-se nas figuras 1 e 2 . 
PINTO, M.S. et al. Contagem bacteriana total do leite cru produzido no Paraná, São Paulo e Minas Gerais após implementação da Instrução Normativa n51/2002. PUBVET, Londrina, V. 6, N. 12, Ed. 199, Art. 1331, 2012.

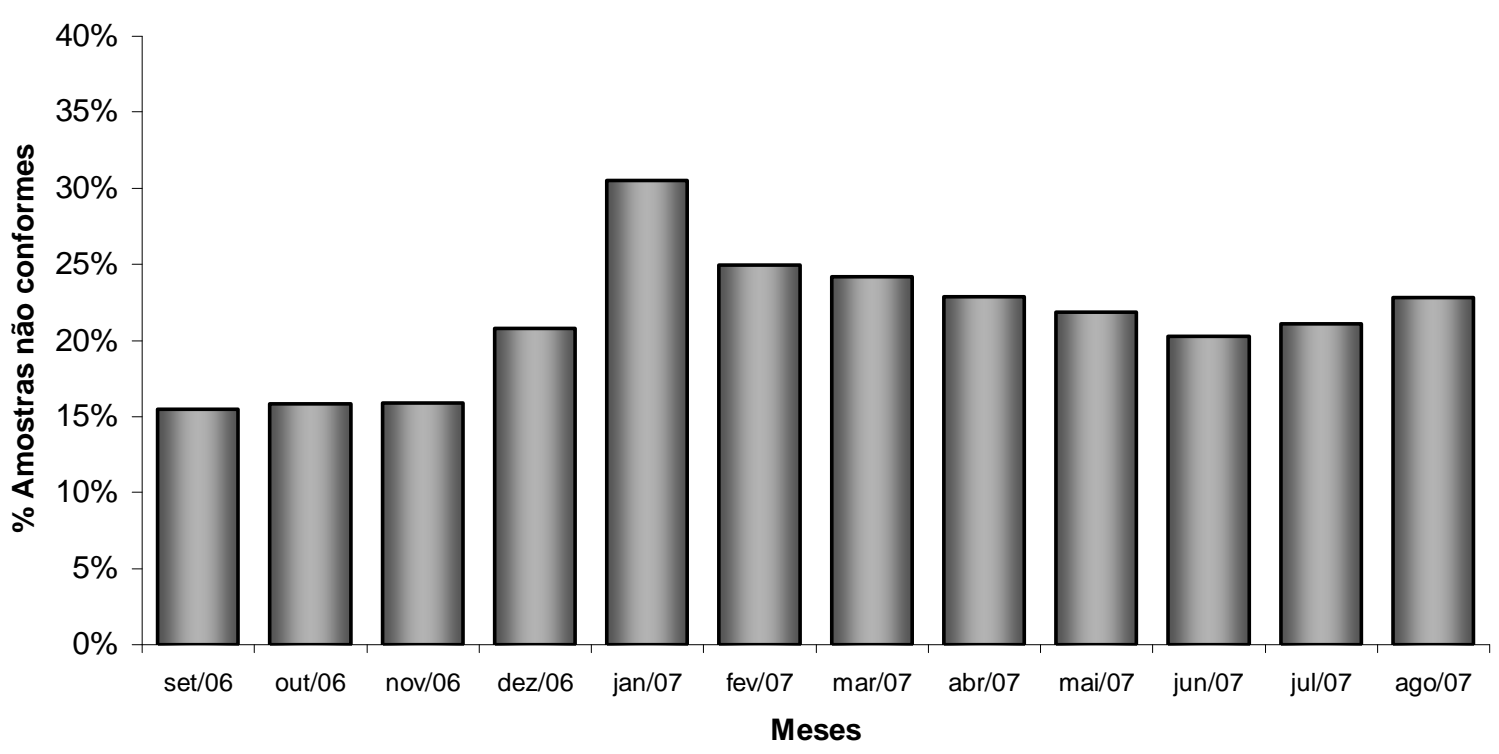

Figura 1: Porcentagem de amostras não conformes para CBT no total

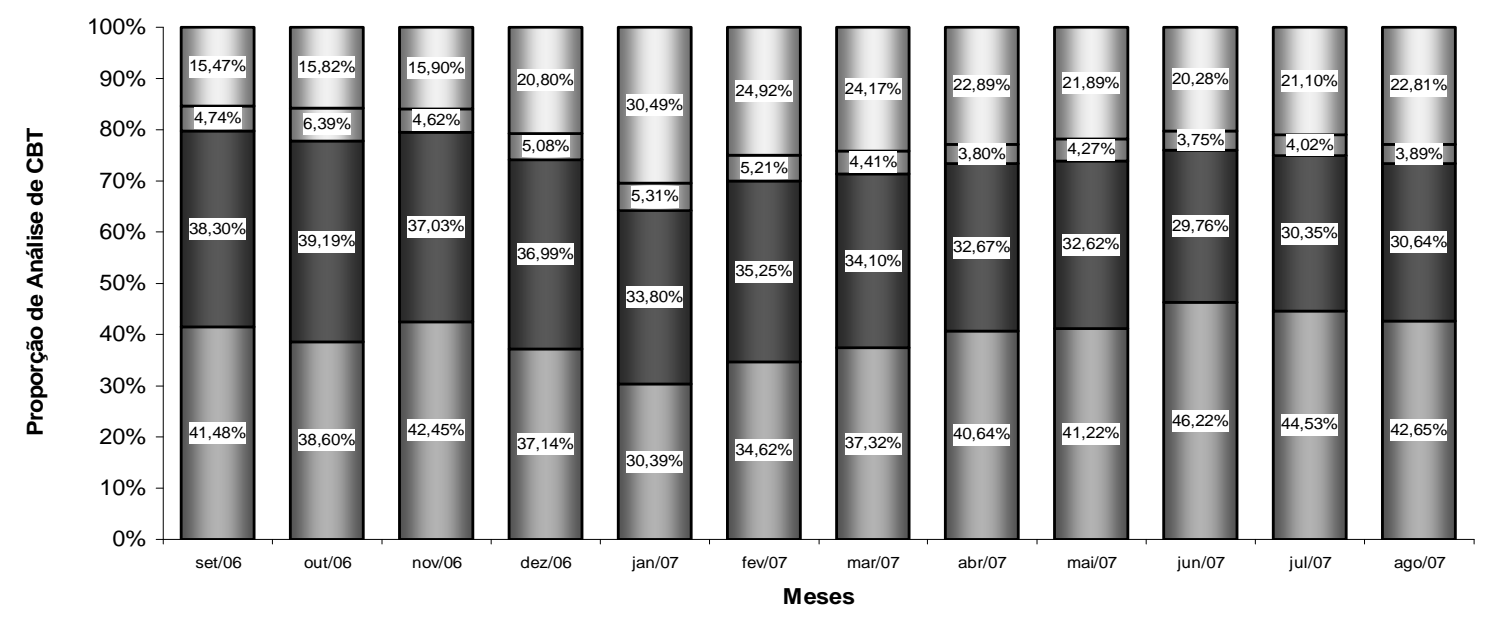

口0 - $100 \square 101-750 \square 751-1000 \square>1000$

Figura 2: Porcentagem dos resultados de CBT obtidos de acordo com as diferentes exigências da IN N51/2002

Analisando por estado, a porcentagem de amostras não conformes com a legislação para CBT em Minas Gerais variou entre 14,08 a 27,94\%, com média de $20 \%$. 
PINTO, M.S. et al. Contagem bacteriana total do leite cru produzido no Paraná, São Paulo e Minas Gerais após implementação da Instrução Normativa n51/2002. PUBVET, Londrina, V. 6, N. 12, Ed. 199, Art. 1331, 2012.

Em São Paulo, a porcentagem de amostras não conformes com a referida legislação para CBT variou entre 14,09 a 35,56\%, com média total de $24 \%$.

No Paraná, os resultados obtidos apresentaram valores entre 8,8 a $22,26 \%$ das amostras em desacordo com o preconizado pela legislação, com média de $16 \%$.

\subsection{MÉDIA GEOMÉTRICA DA CBT}

Os resultados das médias geométricas obtidas em todos os estados e no geral estão expostos na figura 3. As contagens variaram entre $74.000 \mathrm{UFC} / \mathrm{mL}$ - valor encontrado no mês de abril de 2007 no Paraná - e 394.000 UFC/mL valor encontrado em janeiro de 2007 em São Paulo. No estado de São Paulo obtiveram-se os maiores índices, seguido de Minas Gerais e Paraná, porém todos os valores estão dentro dos padrões exigidos pela legislação que estava em vigor na época, que era de até $1 \times 10^{6} \mathrm{UFC} / \mathrm{mL}$, tanto para os estados quanto na média geral.

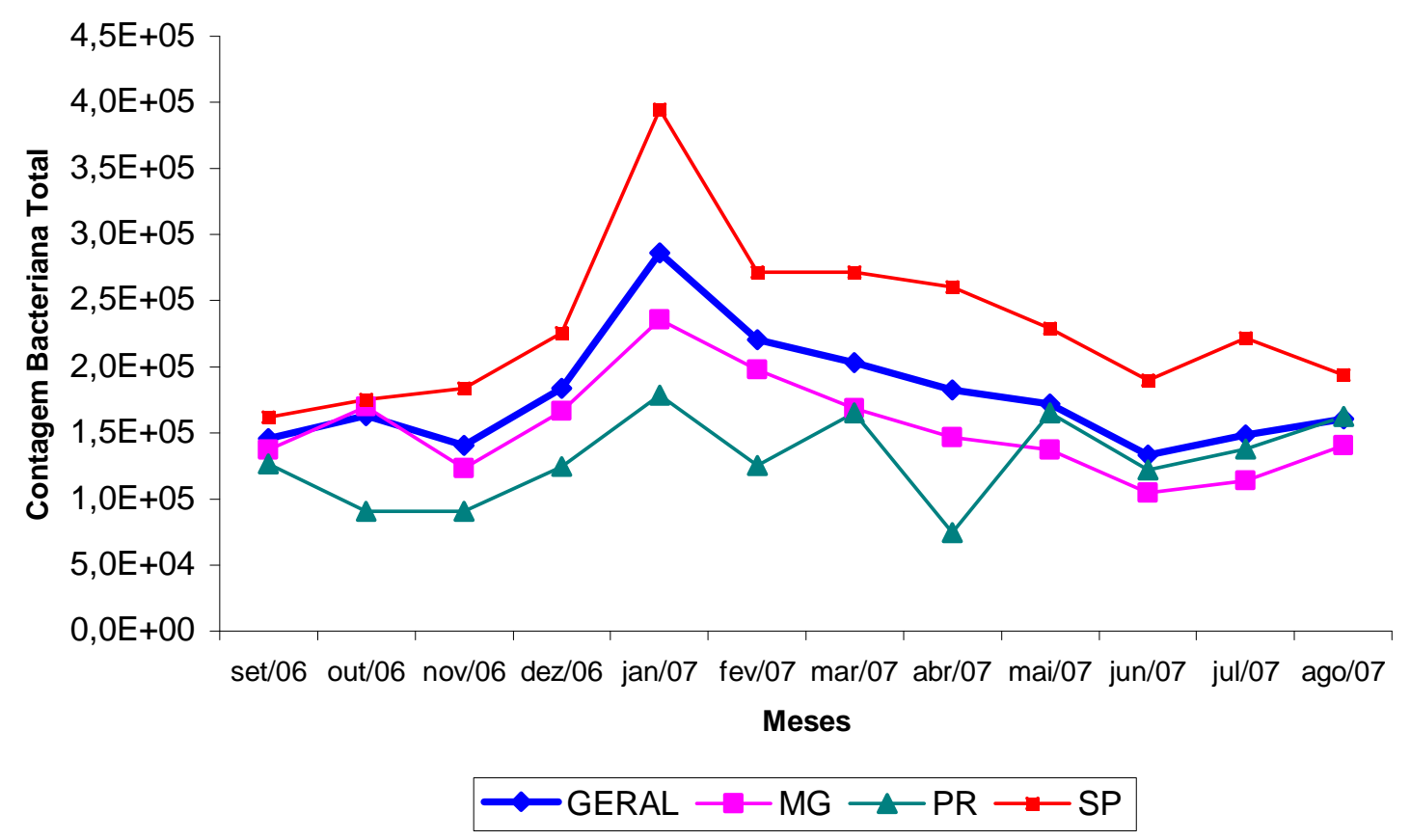

Figura 3: Média Geométrica de CBT durante o período avaliado. 
PINTO, M.S. et al. Contagem bacteriana total do leite cru produzido no Paraná, São Paulo e Minas Gerais após implementação da Instrução Normativa n51/2002. PUBVET, Londrina, V. 6, N. 12, Ed. 199, Art. 1331, 2012.

\section{DISCUSSÃO}

\subsection{PORCENTAGEM DE AMOSTRAS EM DESACORDO COM A IN N51/2002}

Em todos os estados avaliados, a maior porcentagem de não conformidade ocorreu nos meses de janeiro a março, com variação de 30,49\% a $24,17 \%$, período este, quente e úmido (verão).

Souza et al. ${ }^{11}$ encontraram valores elevados de Contagem de Célula Somáticas (CCS) e CBT nesta época do ano, nas amostras de tanques de refrigeração de produtores do Espírito Santo, Minas Gerais e Rio de Janeiro pelo período de 01/07/2005 a 30/06/2006, estando seus resultados em conformidade com os dados encontrados nesta pesquisa. Sugere-se, para tal, que o aumento de CBT nestes meses, pode estar associado à maior população bacteriana no ambiente nesta época do ano, e consequentemente, se o leite não passou por um imediato/eficiente processo de refrigeração, a temperatura ambiental mais alta proporcionou uma maior taxa de proliferação bacteriana. Além disso, o clima quente e úmido predispõe a maior incidência de mastite subclínica no rebanho e um maior número de microrganismos presentes no leite ordenhado, pois segundo Bramley et al. ${ }^{12}$, a contagem bacteriana do leite cru pode aumentar devido à presença de mastite nos animais de produção. Segundo Lange e Brito ${ }^{2}$, vacas infectadas com Streptococcus uberis ou Escherichia coli, importantes agentes etiológicos causadores de mastite, podem eliminar mais do que $10^{7} \mathrm{UFC} / \mathrm{mL}$ de leite, e um único animal infectado pode aumentar muito a CBT no leite do tanque, podendo ser considerado como fator de aumento bacteriano nos achados inclusos neste trabalho.

O estado do Paraná apresentou a menor média da porcentagem (16\%) de amostras em desacordo com a legislação adotada para a análise. O estado de São Paulo obteve resultado de $24 \%$ na média e Minas Gerais teve $20 \%$ das suas amostras em não conformidade com a IN N51/2002 para o limite legal 
PINTO, M.S. et al. Contagem bacteriana total do leite cru produzido no Paraná, São Paulo e Minas Gerais após implementação da Instrução Normativa n51/2002. PUBVET, Londrina, V. 6, N. 12, Ed. 199, Art. 1331, 2012.

vigente na época para os meses avaliados durante o estudo, correspondendo a $1,0 \times 10^{6} \mathrm{UFC} / \mathrm{mL}$.

Comparando os dados obtidos no estado de Minas Gerais com os encontrados por Pinto et al. ${ }^{13}$ que quantificaram valores entre $1,4 \times 10^{6} \mathrm{e}$ $5,5 \times 10^{6} \mathrm{UFC} / \mathrm{mL}$ em amostras de leite cru refrigerado de silos industriais de um laticínio da Zona da Mata mineira, resultados estes em desacordo com o preconizado pela norma vigente na época do estudo, é possível verificar uma grande diferença de resultados, quando confronta-se tais dados com os encontrados no presente estudo. A média geométrica encontrada, referente ao estado de Minas Gerais, variou entre $1 \times 10^{5}$ a $2 \times 10^{5} \mathrm{UFC} / \mathrm{mL}$, sendo estes inferiores aos encontrados no trabalho supracitado.

Machado et al. ${ }^{14}$ pesquisando a CBT de amostras de leite cru refrigerado no estado de Santa Catarina obtiveram resultados entre $58,96 \%$ e $80,45 \%$ das amostras com CBT, acima de um milhão/mL no período de outubro de 2005 a junho de 2006, dados superiores aos encontrados no presente estudo, uma vez que, nas análises realizadas, a porcentagem de resultados em desacordo com a IN N51/2002 variou entre $15,47 \%$ e $30,49 \%$ no total, indicando contaminação bacteriana em grande parte do leite produzido nas propriedades rurais daquela unidade da federação.

Mais uma vez, interpretando-se os dados obtidos, observa-se que existe grande variação na qualidade bacteriológica do leite produzido ao longo do ano em todos os estados. Estes resultados permitem sugerir que o clima do país é fator importante a ser considerado na contagem bacteriana do leite produzido.

Correlacionando a alta contagem bacteriana nos meses de verão com a maior incidência de mastite e CCS, é possível citar autores que verificaram, da mesma forma, o aumento da contagem nestes mesmos meses do ano. De Paula et al. ${ }^{15}$ analisando amostras de leite de tanques refrigeradores no período de janeiro de 1999 a novembro de 2001, encontraram maiores médias de CCS em janeiro com $497.000 \mathrm{cel} / \mathrm{mL}$ e as mais baixas em setembro, com $442.000 \mathrm{cel} / \mathrm{mL}$. 


\subsection{MÉDIA GEOMÉTRICA DOS RESULTADOS DE CBT}

Os valores das médias geométricas obtidas neste trabalho estão abaixo do padrão estabelecido pela Instrução Normativa N051/2002/MAPA vigente no período analisado, sendo que o resultado mais elevado no geral de análises avaliadas deu-se no mês de janeiro de 2007 (286.000 UFC/mL) e o menor no mês de junho de 2007 (133.000 UFC/mL).

Estes dados estão inferiores aos obtidos por Machado et al. ${ }^{14}$, que ao avaliar amostras de leite cru de tanques refrigeradores no estado de Santa Catarina durante o período de outubro de 2005 a junho de 2006, encontraram médias geométricas que variaram de $1.523 .930 \mathrm{UFC} / \mathrm{mL}$ a $3.693 .010 \mathrm{UFC} / \mathrm{mL}$, valores todos acima do estabelecido como parâmetros da norma.

Da mesma forma, Dürr et al. ${ }^{16}$ também encontraram valores elevados $394.000 \mathrm{UFC} / \mathrm{mL}$ a $1.433 .590 \mathrm{UFC} / \mathrm{mL}$ - de CBT em amostras de leite cru refrigerado de tanques do Estado do Rio Grande do Sul, durante o período de julho de 2005 a junho de 2006.

Para a grande diferença entre os valores encontrados nas diferentes regiões expõem-se o fato de que, nos estados amostrados nesta pesquisa, apesar do grande número de análises realizadas, pode existir uma menor representatividade em relação ao total de produtores existentes na região. Logo, não é possível concluir, baseado nestes resultados que o leite desta região possui melhor qualidade do que a produção dos demais estados.

Para tanto, é necessário que os laboratórios da RBQL estejam trabalhando com uniformidade e todos os estabelecimentos do país estejam analisando a matéria-prima de todos os seus fornecedores, para que este tipo de inferência possa ser realizada.

Comparando os resultados obtidos no presente estudo com os encontrados por Machado e Cassoli ${ }^{17}$ através de análises realizadas no mesmo laboratório, porém considerando períodos de análises diferentes, é possível observar que houve melhoria na qualidade bacteriológica do leite amostrado nestas regiões, dado que, os autores supracitados encontraram uma média de 
462 mil UFC/mL de CBT pelo período de julho de 2005 a agosto de 2006 em amostras de leite cru de tanques de diversos estados (Minas Gerais, São Paulo, Paraná, Mato Grosso do Sul e Goiás).

Para este fato, atribui-se um possível aumento da adesão pelas indústrias ao pagamento por qualidade ao produtor. Desta forma, a indústria que preza pela melhor matéria-prima, avalia seus produtores com maior frequência, ao mesmo tempo em que, o fornecedor ao receber seu pagamento baseado na qualidade do seu produto, distribui à indústria um produto de melhor qualidade, fatos estes que desencadeiam em resultados satisfatórios mais frequentes. Este panorama foi relatado por Cassoli e Machado ${ }^{18}$, ao afirmar que o pagamento por qualidade causou grande impacto entre os produtores, uma vez que ao se produzir leite de qualidade superior, a receita aumenta cerca de 10 a $15 \%$.

\section{CONCLUSÃo}

Embora a porcentagem de amostras de leite cru refrigerado em desacordo com a legislação estivesse abaixo da média descrita na literatura e as médias geométricas de CBT estivessem dentro dos parâmetros exigidos na norma vigente na época das análises, os valores ainda se encontravam em níveis elevados. Sendo assim, cabe às indústrias captadoras da matéria-prima, conscientizarem e acompanharem a qualidade do leite produzido pelos seus fornecedores, haja vista, que a planta de processamento é responsável juntamente com o produtor pela qualidade do produto ofertado ao consumidor. Compete ainda aos serviços de fiscalização, a verificação do cumprimento à legislação pelas indústrias, de forma que, não apenas sejam realizadas as análises bacteriológicas, mas que obtenham melhorias nos resultados e consequentemente no produto oferecido ao consumidor, que visa consumir um alimento seguro. 


\section{REFERÊNCIAS}

1. Bramley AJ, McKinnon $\mathrm{CH}$. The microbiology of raw milk. 2.ed. In: Robinson RK (Ed). The microbiology of milk. London, UK: Elsevier Science Publishers; 1990. p. 163-208.

2. Lange CC, Brito JRF. Influência da qualidade do leite na manufatura e vida de prateleira dos produtos lácteos: papel das altas contagens microbianas. In: Brito JR, Portugal JAB (Ed). Diagnóstico da Qualidade do leite, impacto para a indústria e a questão dos resíduos de antibióticos. Juiz de Fora: Embrapa Gado de Leite, EPAMIG/CT/ILCT, 2003. p.119-137.

3. Jay JM. Microbiologia de Alimentos. 6 ed. Porto Alegre: Artmed; 2005. 711p.

4. Tronco VM. Manual para Inspeção da Qualidade do Leite. 3 ed. Santa Maria: Ed da UFSM; 2008. 193p.

5. Mutukumira AN, Feresu SB, Narvhus JA, Abrahamsen RK. Chemical and microbiological quality of raw milk produced by Smallholder farmers in Zimbabwe. J Food Protec. $1996 ; 59(9): 984-7$.

6. Brasil. Ministério da Agricultura, Pecuária e Abastecimento. Instrução Normativa no 51 , de 18 de Setembro de 2002. Aprova os Regulamentos Técnicos de Produção, Identidade, Qualidade, Coleta e Transporte de Leite. Diário Oficial da República Federativa do Brasil. Brasília, DF, 20 set. 2002. Seção 1, p.13-22.

7. Brasil. Ministério da Agricultura, Pecuária e Abastecimento. Instrução Normativa no 62 , de 29 de Dezembro de 2011. Altera o caput, excluir o parágrafo único e inserir os $\S \S 1^{\circ}$ ao $3^{\circ}$, todos do art. $1^{\circ}$ da Instrução Normativa MAPA no 51, de 18 de setembro de 2002. Diário Oficial da República Federativa do Brasil. Brasília, DF, 30 dez. 2011. Seção 1.

8. Cassoli LD, Machado PF. Manual de instruções para coleta e envio de amostras de leite para análise. Piracicaba: ESALQ-USP-Clinica do Leite; 2006. 22p.

9. R - Development Core Team [computer program]. Version 2.6.2. R: A language and environment for statistical computing. R Foundation for Statistical Computing, Vienna, Austria. Available from: http://www.R-project.org. 2008.

10. Minitab for Windows release 14.1. [computer program]. Available from: http:// www.minitab.com. Copyright Inc. 2003/2004.

11. Souza GN, Brito JRF, Faria CG. Qualidade do leite de rebanhos bovinos localizados na Região Sudeste: Espírito Santo, Minas Gerais, Rio de Janeiro, Julho/2005 a junho/2006. In: Mesquita AJ, Dürr JW, Coelho KO (Ed). Perspectivas e Avanços da Qualidade do Leite no Brasil. Goiânia: Talento, 2006. p.39-53.

12. Bramley AJ, McKinnon CH, Staker RT, Simpkin DL.The effect of under infection on the bacterial flora of the bulk milk of ten dairy herds. J Appl Bacteriol. 1990;57:317-323.

13. Pinto CLO, Martins $M L$, Vanetti MCD. Qualidade microbiológica de leite cru refrigerado e isolamento de bactérias psicrotróficas proteolíticas. Cienc Tecnol Aliment. 2006;26(3):645-51.

14. Machado HGP, Pereira IB, Kichel MS. Situação atual da qualidade do leite em Santa Catarina. In: Mesquita AJ, Dürr JW, Coelho KO (Ed). Perspectivas e Avanços da Qualidade do Leite no Brasil. Goiânia: Talento; 2006. p.39-53. 
15. Paula MC, Ribas NP, Monardes HG, Arce JE, Andrade UVC. Contagem de Células Somáticas em amostras de leite. Rev Bras Zootec. 2004;33(5): 1303-08.

16. Dürr JW, Moro DV, Rheinheimer V, Tomazi T. Estado atual da qualidade do leite no Rio Grande do Sul. In: Mesquita AJ, Dürr JW, Coelho KO (Ed). Perspectivas e Avanços da Qualidade do Leite no Brasil. Goiânia: Talento; 2006. p.83-94.

17. Machado PF, Cassoli LD. Diagnóstico da qualidade do leite na Região Sudeste. In: Mesquita AJ, Dürr JW, Coelho KO. Perspectivas e Avanços da Qualidade do Leite no Brasil. Goiânia: Talento; 2006. p.55-72.

18. Cassoli LD, Machado PF. Amostragem de leite para pagamento por qualidade. In: Mesquita AJ, Dürr JW, Coelho KO. Perspectivas e Avanços da Qualidade do Leite no Brasil. Goiânia: Talento; 2006.p.136-148. 